Short report

\title{
Cannulation in patients with large periampullary diverticulum using SpyBite miniforceps
}

\author{
Mahadevan Balkrishanan, Mayank Jain, Chenduran SNK, Sridhar CG, Ravi Ramakrishnan, Jayanthi Venkataraman
}

Global Health City, India

\begin{abstract}
Introduction: Cannulation is difficult in patients with periampullary diverticulum (PAD). The described success rate varies from $61 \%$ to $95.4 \%$.

Material and methods: Four cases with PAD in which, despite repeated attempts, we were unable to locate the papilla and cannulate. To overcome this difficulty, we used SpyBite forceps (Boston Scientific) to pull out the papillary orifice and then perform the cannulation using a sphincterotome introduced through the same working channel.

Results: This method reduced the time required for cannulation. In all four of our cases, we had $100 \%$ success in cannulation.

Conclusions: Use of SpyBite miniforceps in difficult cannulations in patients with PAD is useful and has an excellent success rate.
\end{abstract}

Key words: diverticulum, forceps, cannulation.

\section{Address for correspondence}

Mayank Jain, Gleneagles Global Health City, 439 Cheran Nagar, 600100 Chennai, India, phone: 917312365688 ,

e-mail: mayank4670@rediffmail.com

Periampullary diverticulum (PAD) is a duodenal outpunching characterised by herniation of the mucosa or submucosa that occurs via a defect in the muscle layer within an area of 2 to $3 \mathrm{~cm}$ around the papilla. The prevalence of such diverticula increases with age [1]. Cannulation is difficult in patients with PAD. The described success rate varies from $61 \%$ to $95.4 \%$, which is significantly lower than that observed in patients without PAD [2].

Cannulation of intradiverticular papilla is challenging and time consuming. The majority of failures occur due to the inability of the endoscopist to locate the papilla [3]. Various methods have been described in literature for overcoming this difficulty. Use of biopsy forceps to pull the duodenal mucosa adjacent to the papilla is useful to bring the papillary orifice out of the diverticulum. Another instrument, either a cannula or sphincterotome, can then be introduced and biliary cannulation can be attempted with the coordination of the two instruments [4]. Use of reversed guidewire method [5], double endoscope method [6], balloon dilatation of the diverticular neck [7], endoclip or cap assisted cannulation $[8,9]$, prior pancreatic duct stenting [10], and use of rendezvous technique $[11,12]$ have been described in the literature.

Over the last few years, we too have encountered such difficult cannulations in our department. In our last four cases with PAD, despite repeated attempts, we were unable to locate the papilla and cannulate. To overcome this difficulty, we used SpyBite forceps (Boston Scientific) to pull out the papillary orifice and then perform the cannulation using a sphincterotome introduced through the same working channel. This was done as per previous reports in literature on the use of biopsy forceps for such difficult cannulations [4]. No prior consent for the same was taken from patients and the Ethics Committee was intimated regarding the procedure. This method reduced the time required for cannulation. In all four of our cases, we had $100 \%$ success in cannulation. Moreover, the diameter of the 


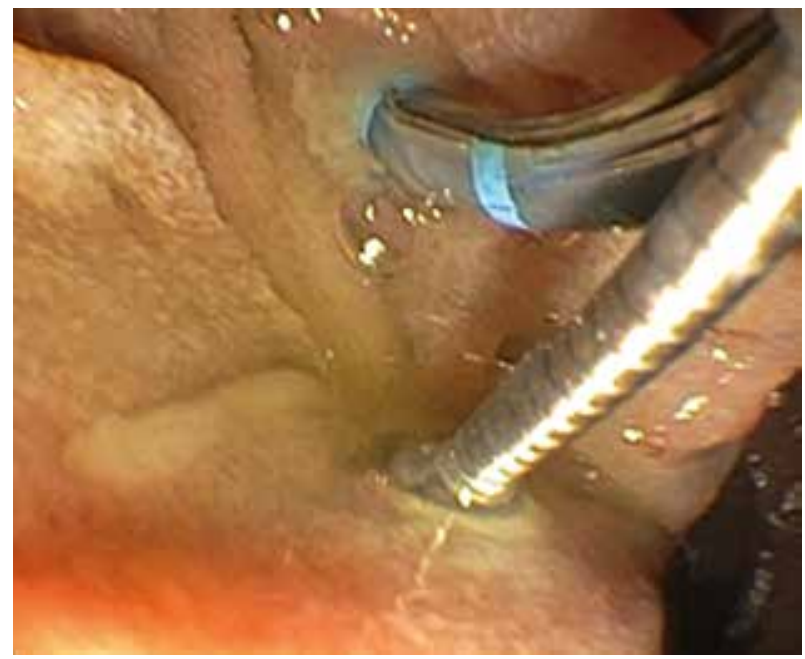

Fig. 1. Cannulation using SpyBite for pulling the papilla

SpyBite forceps was $1 \mathrm{~mm}$, which was much less than standard biopsy forceps, and this eases the manoeuvrability of the accessories to have a higher chance of cannulation. Figure 1 shows simultaneous introduction of SpyBite miniforceps for holding and a sphincterotome for cannulation in one of our cases.

To conclude, use of SpyBite miniforceps in difficult cannulations in patients with PAD is useful and has an excellent success rate.

\section{Disclosure}

Authors report no conflict of interest.

\section{References}

1. Shemesh E, Klein E, Czerniak A, et al. Endoscopic sphincterotomy in patients with gallbladder in situ: the influence of periampullary duodenal diverticula. Surgery 1990; 107: 163-166.

2. Zoepf T, Zoepf DS, Arnold JC, et al. The relationship between juxtapapillary duodenal diverticula and disorders of the biliopancreatic system: analysis of 350 patients. Gastrointest Endosc 2001; 54: 56-61.

3. Tyagi P, Sharma P, Sharma BC, et al. Periampullary diverticula and technical success of endoscopic retrograde cholangiopancreatography. Surg Endosc 2009; 23: 1342-1345.

4. Fujita N, Noda Y, Kobayashi G, et al. ERCP for intradiverticular papilla: two-devices-in-one-channel method. Endoscopic Retrograde Cholangiopancreatography. Gastrointest Endosc 1998; 48: 517-520

5. Elmunzer BJ, Boetticher NC. Reverse guidewire anchoring of the papilla for difficult cannulation due to a periampullary diverticulum. Gastrointest Endosc 2015; 82: 957.

6. Külling D, Haskell E. Double endoscope method to access intradiverticular papilla. Gastrointest Endosc 2005; 62: 811-812.

7. Tóth E, Lindström E, Fork FT. An alternative approach to the inaccessible intradiverticular papilla. Endoscopy 1999; 31: 554-556.
8. Huang CH, Tsou YK, Lin CH, et al. Endoscopic retrograde cholangiopancreatography (ERCP) for intradiverticular papilla: endoclip-assisted biliary cannulation. Endoscopy 2010; 42 Suppl 2: E223-E224.

9. Myung DS, Park CH, Koh HR, et al. Cap-assisted ERCP in patients with difficult cannulation due to periampullary diverticulum. Endoscopy 2014; 46: 352-355.

10. Fogel EL, Sherman S, Lehman GA. Increased selective biliary cannulation rates in the setting of periampullary diverticula: main pancreatic duct stent placement followed by pre-cut biliary sphincterotomy. Gastrointest Endosc 1998; 47: 396-400.

11. Calvo MM, Bujanda L, Heras I, et al. The rendezvous technique for the treatment of choledocholithiasis. Gastrointest Endosc 2001; 54: 511-513. 